\title{
O TRABALHO NO SÉCULO XXI E A BASE NACIONAL COMUM CURRICULAR
}

O entrevistado desta edição, Mozart Neves Ramos, foi um dos participantes do Congresso de Tecnologia na Educação, que ocorreu no Senac em Caruaru em setembro de 2019 - uma parceria dos Departamentos Regionais do Senac e do Serviço Social do Comércio (Sesc) em Pernambuco, em programação conjunta com a Fecomércio do Estado. "Um evento com a participação ativa de professores, gestores e educadores", diz Mozart. Na percapção dele, havia na plateia um grande interesse pela questão da implementação da Base Nacional Comum Curricular (BNCC) nas redes de ensino, tema da mesa-redonda da qual participou juntamente com Francisco Aparecido Cordão - ambos do Conselho Editorial do Boletim Técnico do Senac. O entrevistado destaca, a seguir, os pontos que considera mais pungentes sobre esse tema.

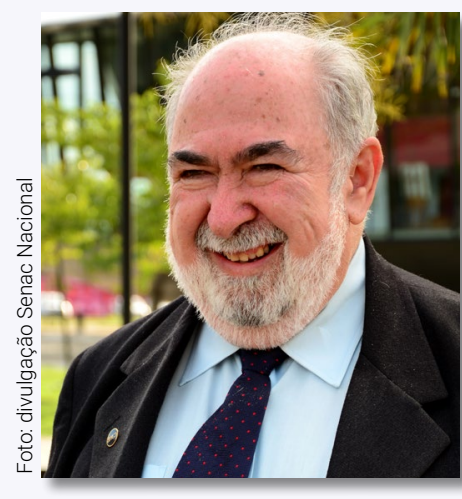

\section{Francisco Aparecido Cordão}

Educador, sociólogo e filósofo. Graduado em Filosofia e Pedagogia. Especialista em Educação Profissional, Administração Educacional e Sociologia da Educação. Atua como Conselheiro nos Conselhos de Educação do Município e do Estado de São Paulo e na Câmara de Educação Básica do Conselho Nacional de Educação (CNE). Representou o Brasil no Mercosul Educacional. Atuou durante mais de trinta anos no Senac em São Paulo. É titular da Cadeira 28 na Academia Paulista de Educação. Presta serviços educacionais a Sistemas, Organizações e Instituições Educacionais, tais como Senac, Sesc e Representação da Organização das Nações Unidas para a Educação, a Ciência e a Cultura (Unesco) no Brasil. E-mail: facordao@uol.com.br

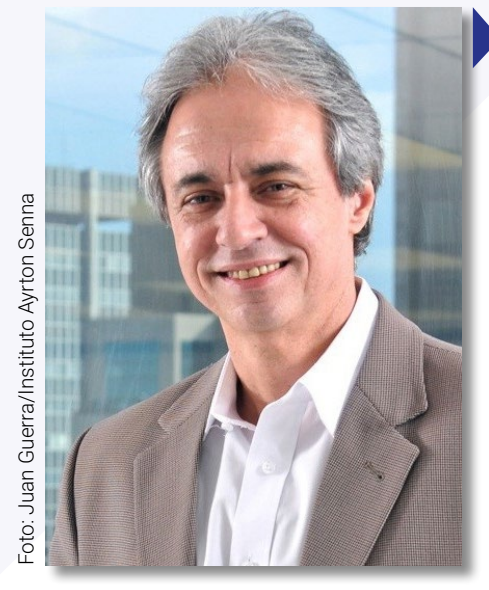

\section{Mozart Neves Ramos}

Foi Professor de Química, Pró-Reitor Acadêmico e Reitor da Universidade Federal de Pernambuco (UFPB). É Doutor em Química pela Universidade Estadual de Campinas (Unicamp) e Pós-Doutor pela Politécnica de Milão - Itália. Foi membro do CNE, presidiu o Fórum Nacional de Pró-Reitores de Graduação das Universidades Brasileiras; a Associação Nacional dos Dirigentes das Instituições Federais de Ensino Superior (Andifes); e o Conselho Nacional de Secretários de Educação (Consed). Foi Secretário de Educação de Pernambuco e Presidente Executivo do Todos Pela Educação. É autor dos livros Educação Sustentável (2006) e Educação Brasileira: Uma Agenda Inadiável (2015), e coautor do livro A Urgência da Educação (2011). Em 2008, foi eleito pela Revista Época uma das 100 pessoas mais influentes do Brasil. Foi agraciado com as seguintes comendas: Personalidade das Artes, Ciências e Letras da França (2006); Educador Internacional do Ano - IBC Cambridge (2005) e Cavaleiro da Ordem do Mérito da República Italiana (2002). Atualmente, é Diretor de Articulação e Inovação do Instituto Ayrton Senna. E-mail: mozart@ias.org.br 
FAC- Nesta manhã, no Congresso de Tecnologia em Educação, realizado por Senac e Serviço Social do Comércio (Sesc), em programação conjunta com a Fecomércio de Pernambuco, palestramos em uma concorrida Mesa de Debates sobre as perspectivas e desafios da implantação da Base Nacional Comum Curricular (BNCC) na Educação Básica Brasileira, desde a etapa inicial da Educação Infantil, passando pelo Ensino Fundamental de nove anos, inclusive para aqueles que não o concluíram na chamada idade própria, culminando no Ensino Médio, etapa de conclusão da Educação Básica, de aprofundamento dos conhecimentos desenvolvidos no Ensino Fundamental. A minha primeira pergunta é a seguinte: de que Educação Básica estamos falando? 0 que está sendo esperado dos jovens brasileiros do século XXI em relação ao mundo do trabalho, em um ambiente cada vez mais complexo, globalizado e competitivo?

MNR- Dentre as competências centrais que serão cobradas dos jovens do século XXI, ao concluírem o seu Ensino Médio, enquanto etapa de conclusão da Educação Básica e de necessário aprofundamento do que foi aprendido até o Ensino Fundamental, destacamos as seguintes competências básicas: Comunicação cada vez mais complexa e exigente; Colaboração e capacidade de trabalhar em equipe; Pensamento crítico e antecipação da solução de problemas; Criatividade e inovação; bem como Informação e fluência nas mídias eletrônicas. A Resolução CNE/CP n. 02/2017, ao instituir e orientar a implantação da BNCC, a ser obrigatoriamente respeitada ao longo de todas as etapas e respectivas modalidades de ensino no âmbito da Educação Básica, em seu Art. 4 , elencou as seguintes dez competências gerais, na condição de expressão dos direitos e objetivos de aprendizagem e desenvolvimento, a serem desenvolvidas pelo estudante, nos termos da atual Lei de Diretrizes e Bases da Educação Nacional (LDB), definida pela Lei n. 9.394/1996 (BRASIL, 1996) e do atual Plano Nacional de Educação (PNE), definido pela Lei n. 13.005/2014 (BRASIL, 2014):

1. Valorizar e utilizar os conhecimentos historicamente construídos sobre o mundo físico, social, cultural e digital para entender e explicar a realidade, continuar aprendendo e colaborar para a construção de uma sociedade justa, democrática e inclusiva;

2. Exercitar a curiosidade intelectual e recorrer à abordagem própria das ciências, incluindo a investigação, a reflexão, a análise crítica, a imaginação e a criatividade, para investigar causas, elaborar e testar hipóteses, formular e resolver problemas e criar soluções (inclusive tecnológicas) com base nos conhecimentos das diferentes áreas;

3. Desenvolver o senso estético para reconhecer, valorizar e fruir as diversas manifestações artísticas e culturais, das locais às mundiais, e também para participar de práticas diversificadas da produção artístico-cultural;

4. Utilizar diferentes linguagens - verbal (oral ou visual-motora, como Libras, e escrita), corporal, visual, sonora e digital -, bem como conhecimentos das lin- 
guagens artística, matemática e científica para se expressar e partilhar informações, experiências, ideias e sentimentos, em diferentes contextos, e produzir sentidos que levem ao entendimento mútuo;

5. Compreender, utilizar e criar tecnologias digitais de informação e comunicação, de forma crítica, significativa, reflexiva e ética nas diversas práticas sociais (incluindo as escolares) para se comunicar, acessar e disseminar informações, produzir conhecimentos, resolver problemas e exercer protagonismo e autoria na vida pessoal e coletiva;

6. Valorizar a diversidade de saberes e vivências culturais e apropriar-se de conhecimentos e experiências que lhe possibilitem entender as relações próprias do mundo do trabalho e fazer escolhas alinhadas ao exercício da cidadania e ao seu projeto de vida, com liberdade, autonomia, consciência crítica e responsabilidade;

7. Argumentar com base em fatos, dados e informações confiáveis para desenvolver, negociar e defender ideias, pontos de vista e decisões comuns que respeitem e promovam os direitos humanos, a consciência socioambiental e o consumo responsável, em âmbito local, regional e global, por meio de um posicionamento ético em relação ao cuidado consigo mesmo, com os outros e com o planeta;

8. Conhecer-se, apreciar-se e cuidar de sua saúde física e emocional, compreendendo-se na diversidade humana e reconhecendo suas emoções e as dos outros, com autocrítica e capacidade para lidar com elas;

9. Exercitar a empatia, o diálogo, a resolução de conflitos, de forma harmônica, e a cooperação, fazendo-se respeitar, bem como promover o respeito ao outro e aos direitos humanos, com acolhimento e valorização da diversidade de indivíduos e de grupos sociais (seus saberes, identidades, culturas e potencialidade) sem preconceitos de qualquer natureza;

10. Agir pessoal e coletivamente com autonomia, responsabilidade, flexibilidade, resiliência e determinação, tomando decisões baseadas em princípios éticos, democráticos, inclusivos, sustentáveis e solidários.

FAC- Essas dez competências gerais descritas pelo Conselho Nacional de Educação devem estar na condição da oferta, por parte das Instituições de Educação Básica, em todas as suas etapas e modalidades de ensino, de um conjunto orgânico e progressivo de aprendizagens essenciais apresentadas e desenvolvidas como direito das crianças, jovens e adultos no âmbito da Educação Básica no ambiente escolar. Sendo assim, de qual Educação vamos precisar para conseguir que, no exercício de sua autonomia, prevista nos artigos 12, 13 e 23 da LDB, as Escolas de Educação Básica possam desenvolver um processo de construção de propostas pedagógicas que, efetivamente, atendam todos os direitos e objetivos de aprendizagem instituídos na BNCC? 
MNR- A referida Resolução do Conselho Nacional de Educação, fundamentada na Constituição Federal, em leis e em demais Atos Normativos da Educação Básica brasileira, bem como no Parecer CNE/CP n. 15/2017, devidamente homologado pela Portaria MEC n. 1.570, de 20 de dezembro de 2017, estabelece que essas aprendizagens essenciais são definidas como conhecimentos, habilidades, atitudes, valores e a capacidade de mobilizá-los, articulá-los e integrá-los expressando-se em competências. Desse modo, as aprendizagens essenciais compõem o processo formativo de todos os educandos ao longo das diferentes etapas e modalidades de ensino, no nível da Educação Básica, objetivando garantir o direito ao "pleno desenvolvimento da pessoa, seu preparo para o exercício da cidadania e qualificação para o trabaIho", conforme definido no Art. $2^{\circ}$ da LDB, reafirmando o princípio constitucional já definido no Art. 2015 da Constituição Federal. No âmbito da BNCC, como muito bem esclarece o Art. $3^{\circ}$ da referida Resolução CNE/CP n. 02/2017, a competência é definida como a mobilização de conhecimentos, em termos de conceitos e procedimentos, das habilidades, em termos de práticas cognitivas e socioemocionais, bem como de atitudes e valores que devem ser mobilizados, articulados e integrados, objetivando resolver demandas complexas da vida cotidiana, do pleno exercício da cidadania e do mundo do trabalho. Nesses termos, a BNCC configura-se como uma referência nacional para os Sistemas de Ensino e para as Instituições ou Redes Escolares, públicas e privadas, da Educação Básica, em todas as suas etapas e modalidades, tanto no âmbito do Sistema Federal de Ensino quanto nos sistemas estaduais, distritais e municipais, orientando-os a construírem ou revisarem seus currículos escolares. Assim, a BNCC deve fundamentar a concepção, formulação, implementação, avaliação e revisão desses currículos e, consequentemente, das propostas pedagógicas das instituições escolares, contribuindo, desse modo, para a articulação e coordenação de políticas e ações educacionais desenvolvidas em âmbito federal, estadual, distrital e municipal, especialmente em relação à formação de professores, à avaliação da aprendizagem, à definição de recursos didáticos e aos critérios definidores de infraestrutura adequada para o pleno desenvolvimento da oferta de educação de qualidade. Assim, a implementação da BNCC deve superar a fragmentação das políticas educacionais, ensejando o fortalecimento do regime de colaboração entre as três esferas de governo e balizando a qualidade da Educação Básica democraticamente ofertada. Para tanto, as propostas pedagógicas das instituições ou redes de ensino devem ser elaboradas e executadas com efetiva participação de seus docentes, os quais devem, consequentemente, definir seus planos de trabalho mantendo estrita coerência com as respectivas propostas pedagógicas, nos termos dos artigos 12 e 13 da LDB. Essas propostas pedagógicas e os currículos de cada curso ofertado, obviamente, devem considerar as múltiplas dimensões de seus estudantes, visando pleno desenvolvimento do indivíduo, na perspectiva de efetivação de uma educação integral, vinculada ao mundo do trabalho e sua prática social. Essa educação integral que almejamos se faz por meio do desenvolvimento de competências que combinem aspectos cognitivos e socioemocionais, possibilitando aos estudantes a capacitação para o autoconhecimento, a colaboração, a criatividade, a resolução de problemas, 
o desenvolvimento do pensamento crítico e a abertura para o novo, na perspectiva da realização do seu projeto de vida.

FAC- Entendo que, realmente, para se conseguir concretizar a efetiva implantação da BNCC na Educação Básica, será necessário garantir, primeiramente, a real participação dos docentes na concepção e no planejamento, bem como na avaliação e no contínuo replanejamento dos Projetos Pedagógicos das Escolas e Redes Escolares, nos termos definidos pelos artigos 12 e 13 da LDB. É essencial considerar, no desenvolvimento do processo de construção das propostas pedagógicas escolares, o atendimento de todos os direitos e objetivos de aprendizagem instituídos na BNCC. Para tanto, as instituições escolares, redes de escolas e seus respectivos sistemas de ensino poderão adotar formas de organização e propostas de progressão que julgarem necessários. Entretanto a pergunta que não quer calar é a seguinte: as Diretrizes Curriculares Nacionais definidas pelo Conselho Nacional de Educação estão suficientemente claras, mas como vamos inserir as competências da BNCC na sala de aula?

MNR- Este é o grande desafio que a nossa Constituição Federal, promulgada em 1988, e a nossa atual LDB, aprovada em 1996, colocam para os educadores brasileiros que atuam nos diversos cursos no âmbito da Educação Básica. Para responder a tua pergunta, de início, vou relembrar, resumidamente, as dez Competências Gerais da BNCC que as Instituições Educacionais devem garantir aos seus educandos no esforço para desenvolver a tarefa atribuída pelo Inciso III do Art. 13 da LDB, em termos de "zelar pela aprendizagem dos alunos". Essas dez Competências Gerais da BNCC podem ser assim anunciadas:

1. Valer-se do conhecimento para transformar a si e ao mundo;

2. Ser curioso e criativo para resolver problemas reais;

3. Ser sensível para apreciar e produzir arte e cultura;

4. Comunicar-se para interagir em diferentes contextos;

5. Ser digital para conviver e produzir;

6. Compreender o mundo do trabalho para projetar seu futuro;

7. Pensar criticamente para se posicionar no mundo;

8. Conhecer-se e cuidar de si para preparar-se para a vida;

9. Colaborar e comprometer-se com o coletivo para conviver;

10. Ser protagonista e responsável para agir e tomar decisões.

Essas dez Competências Gerais da BNCC devem ser assumidas pelos currículos escolares relativos a todas as etapas e modalidades da Educação Básica. Elas são uma referência obrigatória, que deve ser assumida efetivamente pelas Instituições Educacionais, as quais deverão incluir uma parte diversificada, definida de acordo com a LDB e o conjunto das Diretrizes Curriculares Nacionais instituídas pelo CNE, atendendo às características regionais e locais, segundo normas complementares 
estabelecidas pelos órgãos normativos dos respectivos sistemas de ensino. Para tanto, esses currículos escolares, tendo como referência a BNCC, devem ser complementados em cada instituição escolar e em cada rede de ensino por uma parte diversificada, sendo essas duas partes planejadas, executadas e avaliadas como um todo integrado. Assim, os currículos escolares, coerentes com a proposta pedagógica da instituição ou rede de ensino, devem adequar as proposições da BNCC à sua realidade, considerando, para isso o contexto e as características dos estudantes, devendo:

I. Contextualizar os conteúdos curriculares, identificando estratégias para apresentá-los, representá-los, exemplificá-los, conectá-los e torná-los significativos, com base na realidade do lugar e do tempo nos quais as aprendizagens se desenvolvem e são constituídas;

II. Decidir sobre formas de organização dos componentes curriculares - disciplinar, interdisciplinar, transdisciplinar ou pluridisciplinar - e fortalecer a competência pedagógica das equipes escolares, de modo que se adote estratégias mais dinâmicas, interativas e colaborativas em relação à gestão do ensino e da aprendizagem;

III. Selecionar e aplicar metodologias e estratégias didático-pedagógicas diversificadas, recorrendo a ritmos diferenciados e a conteúdos complementares, se necessário, para trabalhar com as necessidades de diferentes grupos de alunos, suas famílias e cultura de origem, suas comunidades, seus grupos de socialização, entre outros fatores;

IV. Conceber e pôr em prática situações e procedimentos para motivar e engajar os estudantes nas aprendizagens;

V. Construir e aplicar procedimentos de avaliação formativa de processo ou de resultado, que levem em conta os contextos e as condições de aprendizagem, tomando tais registros como referência para melhorar o desempenho da instituição escolar, dos professores e dos alunos;

VI. Selecionar, produzir, aplicar e avaliar recursos didáticos e tecnológicos para apoiar o processo de ensinar e aprender;

VII. Criar e disponibilizar materiais de orientação para os professores, bem como manter processos permanentes de desenvolvimento docente, que possibilitem contínuo aperfeiçoamento da gestão do ensino e aprendizagem, em consonância com a proposta pedagógica da instituição ou da rede de ensino;

VIII. Manter processos contínuos de aprendizagem sobre gestão pedagógica e curricular para os demais educadores, no âmbito das instituições ou redes de ensino, em atenção às diretrizes curriculares nacionais, definidas pelo Conselho Nacional de Educação, e normas complementares, definidas pelos respectivos Conselhos de Educação. 


\section{Referências}

BRASIL. Lei n. 9.394, de 20 de dezembro de 1996. Estabelece as diretrizes e bases da educação nacional. Brasília, DF: Presidência da República, Casa Civil, 2011. Disponível em: http://www.planalto.gov.br/ccivil_03/leis/19394.htm.

Acesso em: 10 out. 2019.

BRASIL. Lei n. 13.005, de 25 de junho de 2014. Aprova o Plano Nacional de Educação - PNE e dá outras providências. Brasília, DF: Presidência da República, Casa Civil, 2014. Disponível em: http://www.planalto.gov.br/ccivil_03/_ato20112014/2014/lei/l13005.htm. Acesso em: 10 out. 2019. 